\title{
CHARACTERIZATION OF MIXED-METAL OXIDES USING SYNCHROTRON-BASED TIME-RESOLVED X-RAY DIFFRACTION AND X-RAY ABSORPTION SPECTROSCOPY
}

\author{
José A. Rodriguez", Jonathan C. Hanson", Joaquín L. Brito“", and Amitesh Maiti”“ \\ Department of Chemistry, Brookhaven National Laboratory Upton, NY 11973, USA \\ "Centro de Química, Instituto Venezolano de Investigaciones Científicas (IVIC), \\ Apartado 21827, Caracas 1020-A, Venezuela \\ *.*Molecular Simulations Inc, 9685 Scranton Road, San Diego, CA 92121, USA
}

\begin{abstract}
Experiments are described showing the utility of synchrotron-based time-resolved $\mathrm{x}$-ray diffraction (TR-XRD) and $x$-ray absorption near-edge spectroscopy (XANES) for characterizing the physical and chemical properties of mixed-metal oxides that contain Mo and a second wansition metal ( $\mathrm{Fe}, \mathrm{Co}$ or $\mathrm{Ni}$ ). TR-XRD was used to study the transformations that occui during the heating of a $\mathrm{FeMoO} / \mathrm{Fe}_{2}\left(\mathrm{MoO}_{4}\right)_{3}$ mixture and the $\alpha=\beta$ phase transitions in $\mathrm{CoMoO}_{4}$ and $\mathrm{NiMoO}_{4}$. The $\mathrm{Mo}_{\mathrm{T}^{-}}$and $\mathrm{O} \mathrm{K}$-edges in XANES are very useful for probing the local symmetry of Mo atoms in mixed-metal oxides. The results of XANES and density-functional calculations (DMol3, DFT-GGA) show large changes in the splitting of the empty Mo 4d levels when going from tetrahedral to octahedral coordinations. XANES is very useful for studying the reaction of $\mathrm{H}_{2}, \mathrm{H}_{2} \mathrm{~S}$ and $\mathrm{SO}_{2}$ with the mixed-metal oxides. Measurements at the $\mathrm{S} \mathrm{K}$-edge allow a clear identification of $\mathrm{S}, \mathrm{SO}_{2}, \mathrm{SO}_{3}$ or $\mathrm{SO}_{4}$ on the oxide surfaces. Changes in the oxidation state of molybdenum produce substantial shifts in the position of the $\mathrm{Mo}_{\mathrm{u}^{-}}$and $\mathrm{M}_{\mathrm{m}^{-}}$-edges.
\end{abstract}

\section{INTRODUCTION}

Mixed-metal oxides play a relevant role in many areas of materials science, physics, chemistry, and the electronic industry. In principle, the combination of two metals in an oxide matrix can lead to materials with novel properties and a superior performance in technological applications. In this article we illustrate the use of two synchrotron-based techniques, time-resolved $x$-ray diffraction (TR-XRD) and $\mathrm{x}$-ray absorption near-edge spectroscopy (XANES), in the characterization of the physical and chemical properties of mixed-metal oxides. We focus on the behavior of compounds of the $\mathrm{MeMoO}_{4}$ type $(\mathrm{Me}=\mathrm{Fe}, \mathrm{Co}$ or $\mathrm{Ni})$, which result from adding oxides of the $\mathrm{MeO}$ type to $\mathrm{MoO}_{3}[1]$ and constitute an interesting group of materials due to their structural, electronic and catalytic properties [1-5].

Investigations at Brookhaven National Laboratory has established the feasibility of conducting sub-minute, time-resolved $\mathrm{x}$-ray diffraction experiments under a wide variety of temperature and pressure conditions $\left(-190^{\circ} \mathrm{C}<\mathrm{T}<900{ }^{\circ} \mathrm{C} ; \mathrm{P}<45 \mathrm{~atm}\right)$ [6]. This important advance results from combining the high intensity of synchrotron radiation with new parallel data-collection devices [6]. Examples of problems studied to date with TR-XRD include the hydrothermal synthesis and thermal dehydration of zeolites, the binding of substrates and inhibitors in porous catalytic materials, and phase transformations in oxides $[4,6,7]$. X-ray absorption near-edge a spectroscopy has emerged as a powerful tool for studying the electronic and structural properties of solids [8]. Recently, we have shown that the results of theoretical calculations based on density-functional theory (DFT) can be very useful for explaining the XANES spectra of oxides [7]. 


\section{EXPERIMENTAL}

The time-resolved powder diffraction patterns of the $\mathrm{MeMoO}_{4}$ compounds were collected on beamline X7B of the National Synchrotron Light Source (NSLS) at Brookhaven National Laboratory. The diffraction patterns were accumulated on a flat image plate (IP) detector and retrieved using a Fuji BAS2000 scanner. The XANES spectra of the mixed-metal oxides were collected at the NSLS on beamlines U7A (Mo M-edges and O K-edge) and X19A (Mo L-edges and S K-edge). The measurements at X19 were performed in the "fluorescence-yield mode", whereas the data at U7A were acquired in the "electron-yield mode". The theoretical spectra for the Mo L-edges [7] were calculated using DFT and commercial versions of the CASTEP [9] and DMol3 [10] codes available from Molecular Simulations Inc.

The different isomorphs of the $\mathrm{MeMoO}_{4}$ compounds were prepared following the methodology described in ref. [3]. In a set of experiments, the molybdates were exposed to $\mathrm{H}_{2}$ or $\mathrm{SO}_{2}$ in a RXM-100 instrument from Advanced Scientific Designs. The reduction with hydrogen was carried out in a flow-reactor with a $15 \% \mathrm{H}_{2} / 85 \% \mathrm{~N}_{2}$ mixture (flow rate $=50 \mathrm{~cm}^{3} / \mathrm{min}$ ) and the temperature was ramped from 40 to 650 or $800^{\circ} \mathrm{C}$ (heating rate $=20^{\circ} \mathrm{C} / \mathrm{min}$ ). Pure oxide powders were exposed to $\mathrm{SO}_{2}$ in a reaction cell ("batch sonta- mode") at $50^{\circ} \mathrm{C}$ for 15 min with a constant $\mathrm{SO}_{2}$ pressure of 10 Torr.

\section{RESULTS}

Phase transitions and studies using time-resolved $x$-ray diffraction. Under atmospheric pressure the $\mathrm{MeMoO}_{4}$ compounds can adopt a low temperature $\alpha$-phase in which Mo and the second metal ( $\mathrm{Fe}, \mathrm{Co}$ or $\mathrm{Ni}$ ) are in an octahedral coordination, or a high temperature $\beta$-phase in which $\mathrm{Mo}$ is in a tetrahedral environment with the second metal remaining in octahedral coordination $[1,4,7]$. Using TR-XRD we monitored the $\alpha=\beta$ phase transitions in $\mathrm{CoMoO}_{4}$ and $\mathrm{NiMoO}_{4}[4,7]$. Figure 1 shows that in the case of the cobalt molybdate the transformation occurs

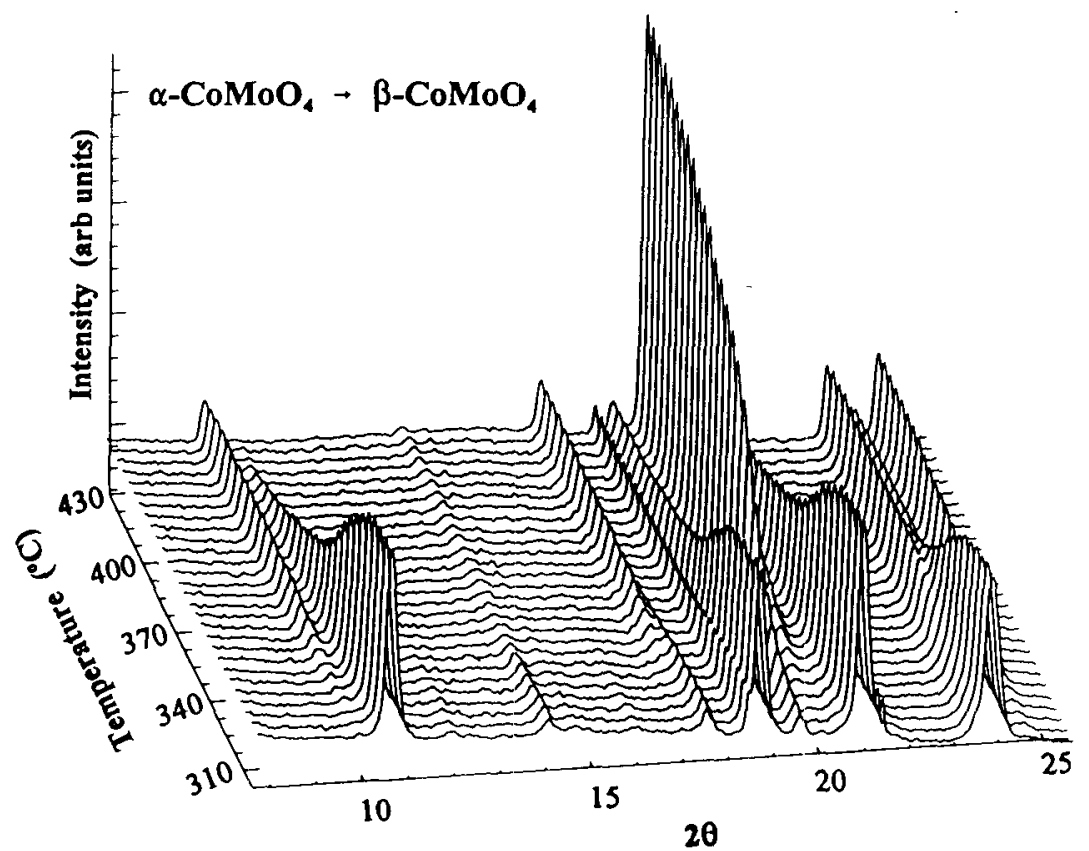

Fig 1 Time-resolved $x$-ray diffraction patterns for the $\alpha \Rightarrow \beta$ transition in $\mathrm{CoMoO}$. Heating rate $=1.6^{\circ} \mathrm{C} / \mathrm{min}$ 
between 330 and $410^{\circ} \mathrm{C}$. For the nickel molybdate, the transformation takes place at much higher temperatures: $530-630^{\circ} \mathrm{C}[4,7]$. There are no intermediates in the $\alpha \rightarrow \beta$ transitions for these molybdates: the diffraction lines for $\alpha-\mathrm{MeMoO}_{4}$ disappear and simultaneously the lines for $\beta$ $\mathrm{MeMoO}_{4}$ appear. First-principles density-functional calculations carried out with the CASTEP program (DFT-GGA level) show that $\alpha-\mathrm{CoMoO}_{4}$ is $\sim 5 \mathrm{kcal} / \mathrm{mol}$ more stable than $\beta-\mathrm{CoMoO}_{4}$ $[7,11]$. On the other hand, $\alpha-\mathrm{NiMoO}_{4}$ is $\sim 9 \mathrm{kcal} / \mathrm{mol}$ more stable than $\beta-\mathrm{NiMoO}_{4}$ [7]. For the $\alpha \Leftrightarrow \beta$ transition in $\mathrm{NiMoO}_{4}$, the DFT calculations predict an energy barrier of $\sim 50 \mathrm{kcal} / \mathrm{mol}$ [7]. The results of TR-XRD indicate that the $\alpha-\mathrm{NiMoO}_{4} \rightarrow \beta-\mathrm{NiMoO}_{4}$ transformation follows a kinetics of first order with an apparent activation energy of $\sim 80 \mathrm{kcal} / \mathrm{mol}[4,7]$.

In the case of the iron molybdate, the procedure followed for the synthesis of the compound [3] in some situations can yield a mixture of $\beta-\mathrm{FeMoO}_{4}, \mathrm{Fe}_{2}\left(\mathrm{MoO}_{4}\right)_{3}$ and an amorphous $\mathrm{FeMo}_{x} \mathrm{O}_{y}$ phase due to the possibility of changes in the oxidation states of the second metal and molybdenum (i.e. $\mathrm{Fe}^{2+}=\mathrm{Fe}^{3+}$ and $\mathrm{Mo}^{6+}=\mathrm{Mo}^{5+}$ ). The evolution of this type of system as a function of temperature can be monitored using TR-XRD. In Figure 2 diffraction lines are observed for $\beta$-FeMoO $4[1,3]$ and $\mathrm{Fe}_{2}\left(\mathrm{MoO}_{4}\right)_{3}$ [12] at low temperatures $\left(<300^{\circ} \mathrm{C}\right)$. The relative intensity of these lines indicates that the $\mathrm{Fe}_{2}\left(\mathrm{MoO}_{4}\right)_{3} / \beta-\mathrm{FeMoO}$ ratio in the sample is $\sim 0.2$. Upon heating one sees the disappearance of the lines for $\mathrm{Fe}_{2}\left(\mathrm{MoO}_{4}\right)_{3}$ at temperatures between 350 and $430{ }^{\circ} \mathrm{C}$. Above $430{ }^{\circ} \mathrm{C}$, only diffraction lines for $\beta-\mathrm{FeMoO}$ are observed but there is a continuous increase in the intensity of these lines. On the basis of the TR-XRD results, one can conclude that $\mathrm{Fe}_{2}\left(\mathrm{MoO}_{4}\right)_{3}$ and the amorphous $\mathrm{FeMo}_{x} \mathrm{O}_{\mathrm{y}}$ phase transform into $\beta-\mathrm{FeMoO}_{4}$ at high temperatures $\left(350-700^{\circ} \mathrm{C}\right)$.

In addition of being a valuable technique for studying phase transitions, we have found that TR-XRD is also very useful for studying structural changes that occur during cycles of reduction (with $\mathrm{H}_{2}$ )/oxidation(with $\mathrm{O}_{2}$ ) or during the reaction of $\mathrm{H}_{2} \mathrm{~S}$ with the molybdates $[11,13]$.

Studies using $x$-ray absorption near-edge spectroscopy. The left-side panel in Figure 3 shows $\mathrm{Mo}_{\mathbb{T}^{-}}$edge XANES spectra for $\mathrm{MoO}_{3}$, the $\beta-\mathrm{FeMoO}_{4} / \mathrm{Fe}_{2}\left(\mathrm{MoO}_{4}\right)_{3} / \mathrm{FeMo}_{\mathrm{x}} \mathrm{O}_{\mathrm{y}}$ mixture of Figure $2\left(\mathrm{~T}=25^{\circ} \mathrm{C}\right)$, and $\beta-\mathrm{FeMoO}_{4}$. These spectra involve transitions from the $2 \mathrm{p}$ core levels into the

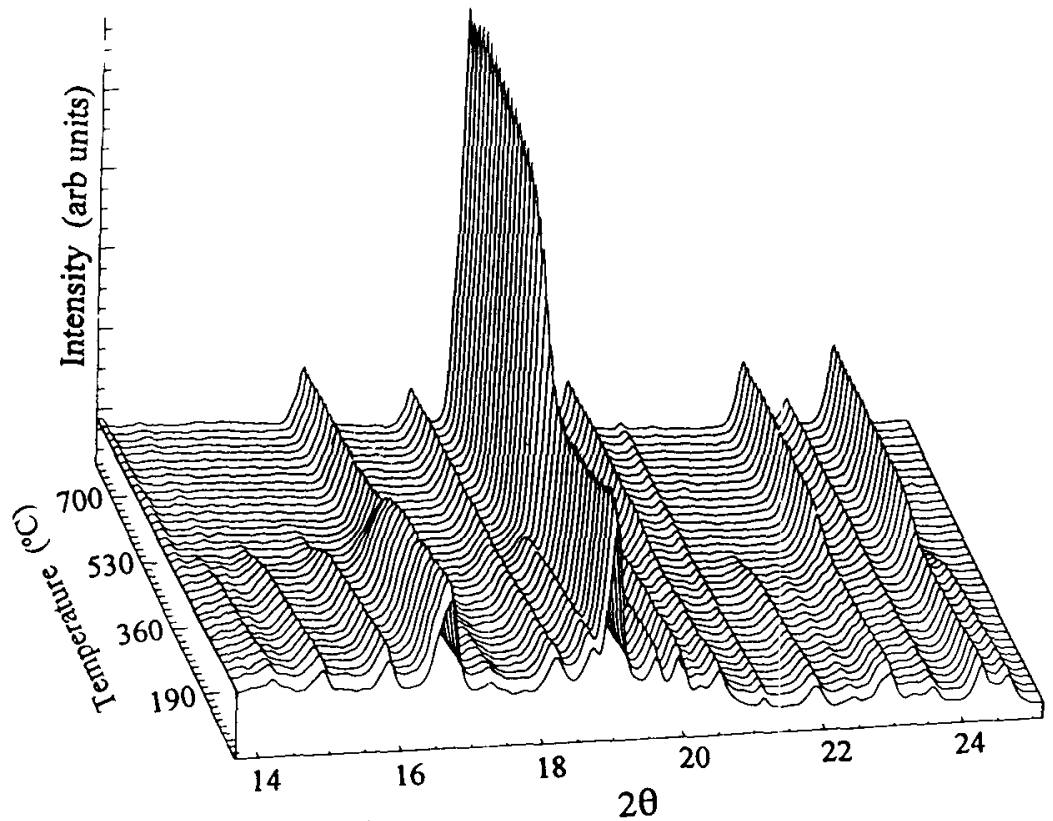

Fig 2 Time-resolved x-ray diffraction patterns for the heating $\left(1.8^{\circ} \mathrm{C} / \mathrm{min}\right)$ of a mixture of $\beta-\mathrm{FeMOO}_{4}, \mathrm{Fe}_{2}\left(\mathrm{MoO}_{4}\right)_{3}$, and an amorphous $\mathrm{FeMo}_{x} \mathrm{O}_{y}$ phase. 

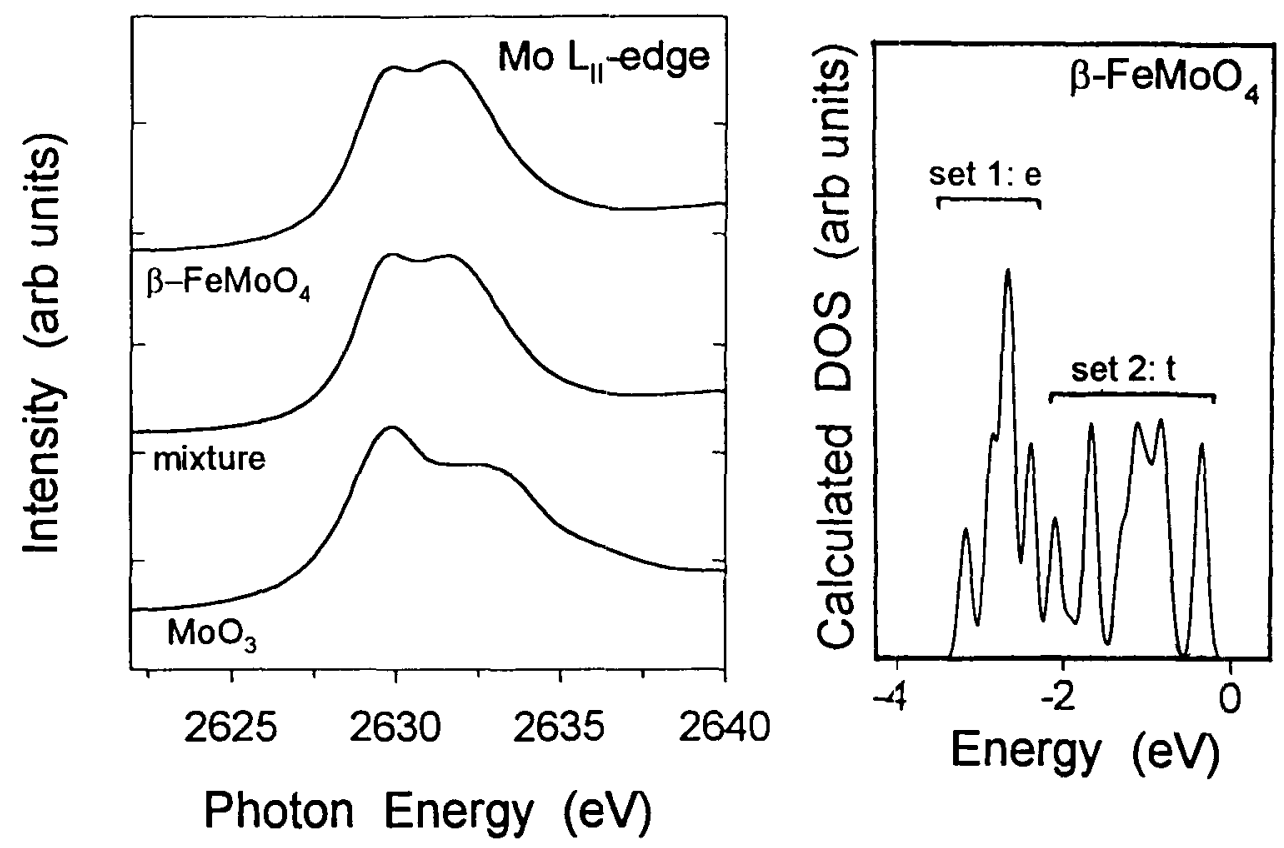

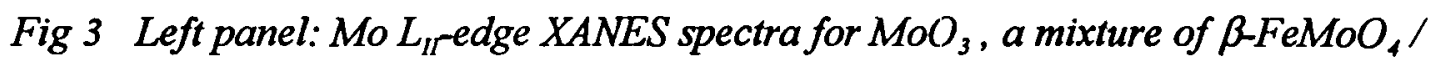
$\mathrm{Fe}_{2}\left(\mathrm{MoO}_{4}\right)_{3} / \mathrm{FeMo}_{x} \mathrm{O}_{y}$, and $\beta-\mathrm{FeMoO}_{4}$. Right panel: Calculated DOS for the empty Mo $4 d$ bands of $\beta-\mathrm{FeMOO}_{4}$ (DMol3, DFT-GGA results).

empty $4 \mathrm{~d}$ orbitals of Mo. The right-side panel in Figure 3 displays the calculated density of states (DMol3, DFT-GGA) for the empty $4 \mathrm{~d}$ bands of $\mathrm{Mo}$ in $\beta-\mathrm{FeMoO}_{4}$. In octahedral and tetrahedral environment, the Mo $4 \mathrm{~d}$ orbitals split in two sets of bands with $t$ and e symmetry as a result of the ligand field generated by the oxygens around the Mo atoms. In a tetrahedral coordination the set with e symmetry is more stable than the set with $t$ symmetry (Fig 3 ). The opposite is valid for an octahedral coordination [7]. The energy separation between the two sets of bands is larger in an octahedral configuration. In Figure 3, the XANES spectra of the oxide mixture and $\beta-\mathrm{FeMoO}_{4}$ show a peak-to-peak separation of $\sim 1.7 \mathrm{eV}$ which is typical of Mo in a tetrahedral environment (see Table I). On the other hand, in the XANES spectrum for $\mathrm{MoO}_{3}$, the peak-to-peak separation is $\sim 3.4 \mathrm{eV}$, a value representative of Mo in octahedral coordination (Table $\mathrm{I}$ ). We have found that the peak-to-peak separations in the $\mathrm{Mo}_{\mathrm{T}}$-edge and $\mathrm{O} \mathrm{K}$-edge of the XANES spectra for the molybdates give direct and reliable information about the coordination of Mo in these systems (see Table I). The case of the $\mathrm{O} \mathrm{K}$-edge spectra is particularly interesting since, due to orbital mixing, one can have electron transfer from the $\mathrm{O} 1 \mathrm{~s}$ orbitals into the empty orbitals of both metals

Table I: Splitting of $M O L_{I r}$ and $O K$ Kedges in XANES

$\begin{array}{lcc}\text { Compound } & \text { Mo Ln }- \text { edge }(\mathrm{eV}) & \text { OK-edge }(\mathrm{eV}) \\ \mathrm{MoO}_{3} & 3.2\left(\mathrm{O}_{\mathrm{h}}\right) & 3.4 \\ \alpha-\mathrm{NiMoO}_{4} & 3.1\left(\mathrm{O}_{\mathrm{h}}\right) & 3.2 \\ \alpha-\mathrm{CoMoO}_{4} & 2.8\left(\mathrm{O}_{\mathrm{h}}\right) & 3.2 \\ \beta-\mathrm{FeMoO}_{4} & 1.6\left(\mathrm{~T}_{\mathrm{d}}\right) & 1.8 \\ \beta-\mathrm{CoMoO}_{4} & 1.5\left(\mathrm{~T}_{\mathrm{d}}\right) & 1.9 \\ \beta-\mathrm{NiMoO}_{4} & 1.7\left(\mathrm{~T}_{\mathrm{d}}\right) & 1.9 \\ \beta-\mathrm{MgMoO}_{4} & 1.6\left(\mathrm{~T}_{\mathrm{d}}\right) & 1.9\end{array}$


present in a molybdate. The results of DFT calculations indicate that this transfer should occur mainly into the unoccupied Mo $4 \mathrm{~d}$ bands $[7,11]$, and indeed the XANES experiments show that the line-shapes in the $\mathrm{O} \mathrm{K}$-edge spectra track very well those observed in the corresponding Mo $\mathrm{L}_{\mathrm{T}}$-edge spectra $[4,7,11]$.

XANES is very useful to study electronic perturbations induced on the molybdates by reaction with $\mathrm{H}_{2} \mathrm{H}_{2} \mathrm{~S}$ or $\mathrm{SO}_{2}$. As an example, Figure 4 shows $\mathrm{Mo}_{\mathrm{m}}$-edge XANES spectra recorded after partially reducing samples of $\beta-\mathrm{FeMoO}_{4}$ by exposing them to a stream of $15 \%-\mathrm{H}_{2} / 85 \%-\mathrm{N}_{2}$. Spectra of temperature programmed reduction (TPR) indicate that the molybdate reacts only with a minor amount of $\mathrm{H}_{2}$ at temperatures below $650^{\circ} \mathrm{C}$, and the consumption of hydrogen becomes larger at temperatures between 650 and $800^{\circ} \mathrm{C} \mathrm{[3]}$. This is consistent with the trends seen in Figure 4. In this figure, the reaction with $\mathrm{H}_{2}$ induces a shift of the $\mathrm{Mo} \mathrm{L}_{\mathbf{n}}$-edge features towards lower photon energies which indicates a reduction in the oxidation state of Mo in the sample.

The $\mathrm{MeMoO}_{4}$ compounds are precursors of hydrodesulfurization catalysts [3] and can be used as sorbents of $\mathrm{SO}_{2}$. Changes in the position of the Mo $\mathrm{M}_{\mathrm{m}^{-}}$-edge in XANES have proven to be quite useful for monitoring the degree of sulfidation of Mo during the reaction of nickel molybdate with $\mathrm{H}_{2} \mathrm{~S}[13,14]$. Measurements at the $\mathrm{S} \mathrm{K}$-edge show the formation of metal sulfides and sulfatac $a c_{2}$ result of the reaction of hydrogen sulfide with iron, cobalt and nickel molybdates $[11,13,14]$. Figure 5 displays a $\mathrm{S} \mathrm{K}$-edge XANES spectrum collected after dosing $\mathrm{SO}_{2}$ to $\beta$ $\mathrm{FeMoO}_{4}$ at $50{ }^{\circ} \mathrm{C}$. There are two clear peaks that correspond to $\mathrm{SO}_{3}\left(\sim 2478 \mathrm{eV}\right.$ [14]) and $\mathrm{SO}_{4}$ $\left(\sim 2482 \mathrm{eV}\right.$ [14]) produced by reaction of $\mathrm{SO}_{2}$ with $\mathrm{O}$ atoms from the lattice of the oxide substrate. A very weak feature is seen around $2474 \mathrm{eV}$ that could be attributed to a very small amount of chemisorbed $\mathrm{SO}_{2}$. There was no dissociation of the adsorbed $\mathrm{SO}_{2}$ and no peaks are seen for metal sulfides or pure sulfur in the XANES spectrum. Our experiments indicate that $\beta-\mathrm{FeMoO}_{4}$ is much more reactive towards $\mathrm{SO}_{2}$ than $\mathrm{MoO}_{3}$, but less reactive than $\mathrm{Fe}_{2} \mathrm{O}_{3}$. The main product of the interaction of $\mathrm{SO}_{2}$ with $\beta-\mathrm{FeMoO}_{4}$ and $\mathrm{Fe}_{2} \mathrm{O}_{3}$ is $\mathrm{SO}_{4}$. This sulfate species is stable on the oxides up to temperatures well above $300^{\circ} \mathrm{C}$.

In summary, the experiments described above show that the combination of two synchrotronbased techniques like time-resolved $\mathrm{x}$-ray diffraction and $\mathrm{x}$-ray absorption spectroscopy can provide detailed information about the structure, phase transitions, electronic properties and

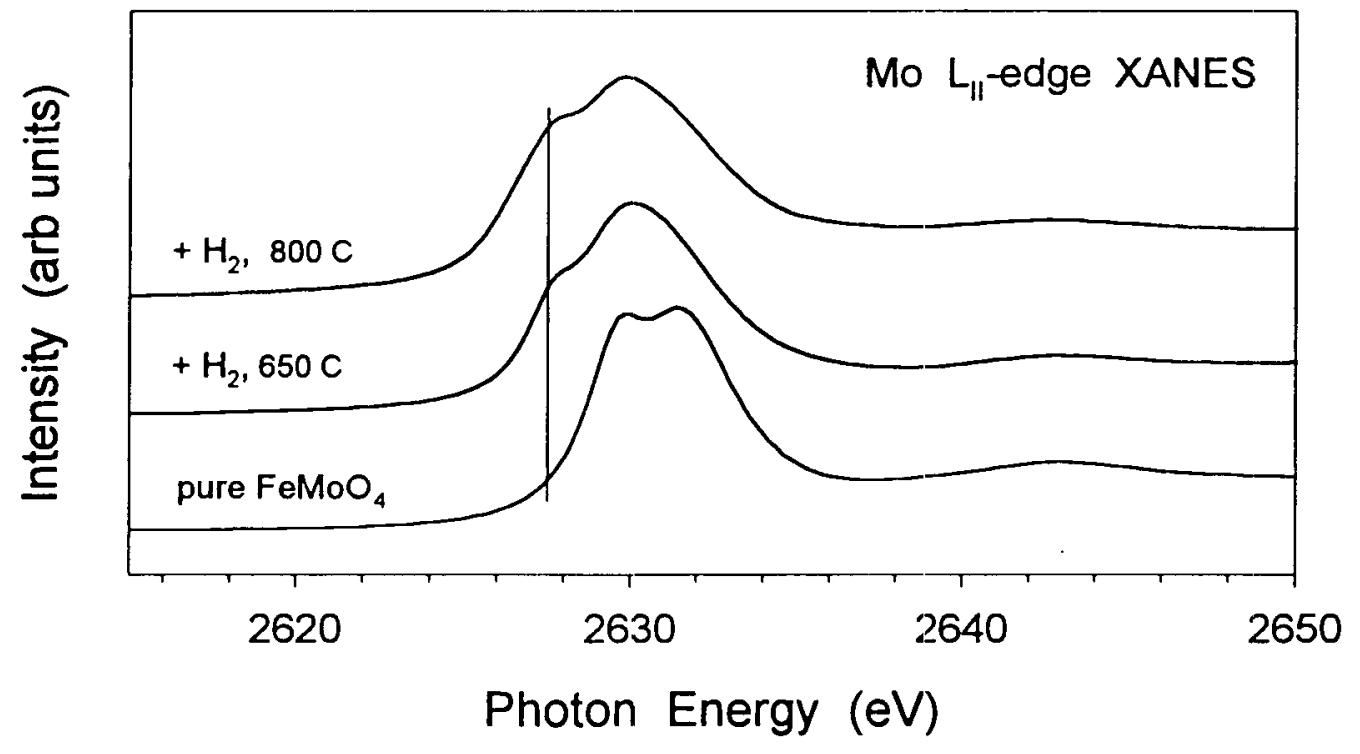

Fig 4 Mo L LI edge XANES spectra acquired before and after exposing $\beta$-FeMoO to a $15 \%-\mathrm{H}_{2} / 85 \%-\mathrm{N}_{2}$ mixture at $40-650^{\circ} \mathrm{C}$ or $40-800^{\circ} \mathrm{C}$ 


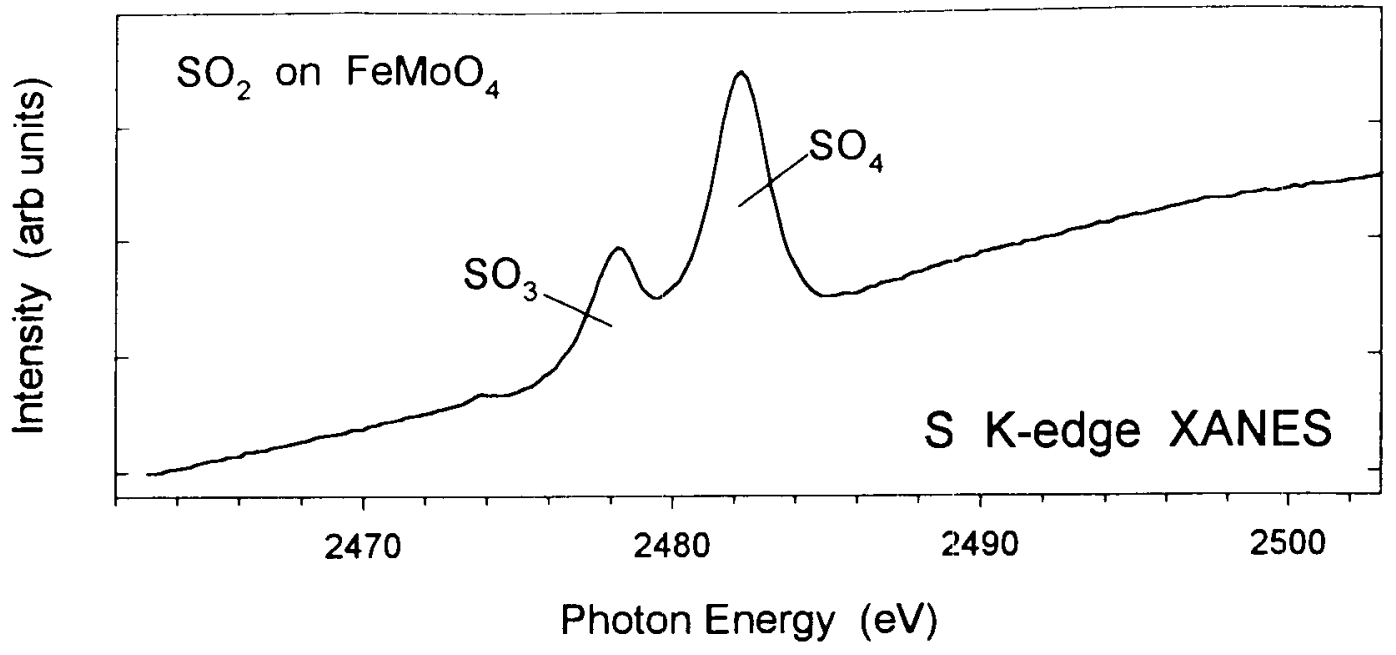

Fig 5 Adsorption of $\mathrm{SO}_{2}$ on $\mathrm{\beta}-\mathrm{FeMoO}{ }_{4}$ at $50^{\circ} \mathrm{C}$

chemical activity of mixed-metal oxides. Following this approach one can get a better understanding of the behavior of this important type of materials.

\section{ACKNOWLEDGMENT}

This work was supported by the US Department of Energy (DE-AC02-98CH10886), Basic Energy Sciences, Chemical Science Division. Travel grants from the American Chemical Society made possible visits of J.L. Brito to BNL and J.A. Rodriguez to IVIC. The facilities used at the NSLS (X7B, X19 and U7A beamlines) are supported by the Chemical and Materials Science Divisions of the US Department of Energy.

\section{REFERENCES}

1. A.W. Sleight and B.L. Chamberland, Inorg. Chem. 7, p. 1672 (1968).

2. J. Zou and G.L. Schrader, J. Catal. 161, p. 667 (1996).

3. J.L. Brito and A.L. Barbosa, J. Catal. 171, p. 467 (1997).

4. J.A. Rodriguez, S. Chaturvedi, J.C. Hanson, A. Albornoz and J.L. Brito, J. Phys. Chem. B, 102, p. 1347 (1998).

5. C. Mazzochia, C. Aboumrad, C. Diagne, E. Tempesti, J.M. Herrmann and G.Thomas, Catal. Lett. 10, p. 181 (1991).

6. P. Norby and J.C. Hanson, Catal. Today, 39, p. 301 (1998).

7. J.A. Rodriguez, J.C. Hanson, S. Chaturvedi, A. Maiti and J.L. Brito, J. Chem. Phys. 112, in press (2000).

8. J.G. Chen, Surf. Sci. Rep. 30, p. 1 (1997).

9. M.C. Payne, D.C. Allan, T.A. Arias and J.D. Johannopoulus, Rev. Mod. Phys. 64, p. 1045 (1992).

10. B. Delley, J. Schefer and T. Woike, J. Chem. Phys. 107, p. 10067 (1997).

11. J.A. Rodriguez, J.C. Hanson and J.L. Brito, to be published.

12. A.W. Sleight and L.H. Brixner, J. Solid State Chem. 7, p. 172 (1973).

13. J.A. Rodriguez, S. Chaturvedi, J.C. Hanson and J.L. Brito, J. Phys. Chem. B, 103, p. 770 (1999).

14. S. Chaturvedi, J.A. Rodriguez and J.L. Brito, Catal. Lett. 51, p. 85 (1998). 